\title{
miR-512-5p suppresses proliferation, migration and invasion, and induces apoptosis in non-small cell lung cancer cells by targeting ETS1
}

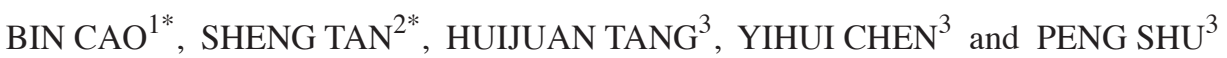 \\ ${ }^{1}$ Department of Cardiothoracic Surgery, The Affiliated Drum Tower Hospital of Nanjing University Medical School, \\ Nanjing, Jiangsu 210005; ${ }^{2}$ Department of Cardio-Thoracic Surgery, The Affiliated Hospital of Xuzhou Medical College, \\ Xuzhou, Jiangsu 221000; ${ }^{3}$ Department of Oncology, Jiangsu Provincial Hospital of \\ Traditional Chinese Medicine, Nanjing, Jiangsu 210005, P.R. China
}

Received May 14, 2018; Accepted February 6, 2019

DOI: $10.3892 / \mathrm{mmr} .2019 .10022$

\begin{abstract}
An increasing number of microRNA (miRNA) have been demonstrated to serve as molecular biomarkers for tumor cell progression. miR-512-5p was revealed as oncogenic regulator in several types of cancer. However, whether and how miR-512-5p regulates non-small cell lung cancer (NSCLC) remains unclear. In the present study, the expression of miR-512-5p was detected in NSCLC tissues and cell lines. Then, the proliferation, migration, invasion and apoptosis in NSCLC A549 and H1299 cell lines were detected when miR-512-5p was overexpressed. Furthermore, the underlying mechanism was identified. The level of miR-512-5p was decreased in NSCLC tissues and in NSCLC cells compared with adjacent normal tissues and normal lung tissue cell lines. miR-512-5p mimics inhibited the cell proliferation, migration, invasion and induced apoptosis in A549 and H1299 cells. In addition, a luciferase reporter assay suggested that overexpression of miR-512-5p may decrease the expression of the E26 transformation specific-1 (ETS1) gene; it was subsequently verified that downregulation of the ETS1 gene inhibited cell proliferation and migration and induced cell apoptosis in A549 and H1299 cells, and ETS1 small interfering RNA in the presence of an miR-512-5p inhibitor reversed the effect. The data described in the present study suggest that miR-512-5p may be a tumor suppressor and a potential treatment target in NSCLC.
\end{abstract}

Correspondence to: Dr Peng Shu, Department of Oncology, Jiangsu Provincial Hospital of Traditional Chinese Medicine, Nanjing, Jiangsu 210005, P.R. China

E-mail: shupeng18@126.com

*Contributed equally

Key words: microRNA-512-5p, proliferation, migration, invasion, apoptosis, E26 transformation specific-1

\section{Introduction}

According to recent estimates from the International Agency for Research on Cancer of the World Health Organization, the total number of lung cancer cases represents $20 \%$ in all malignant tumors, and the mortalities account for $25.4 \%$ of all cancer-associated mortalities (1). In China, with the increases in the size of the aging population, changes in lifestyle, and economic and environmental factors, the incidence and mortality rate of lung cancer are increasing consistently (2). In all patients with lung cancer, non-small cell lung cancer (NSCLC) represents $>80 \%$ cases (3). NSCLC is not easily diagnosed. The majority of patients are diagnosed with mid- and late-stage disease and are not suitable for surgical treatment. Although medical technology has improved in previous years, the early diagnosis, comprehensive management and prognosis of patients with NSCLC remain unsatisfactory. The use of effective diagnostic and therapeutic methods for early detection and early treatment have become an important issue in the control of NSCLC.

MicroRNAs (miRNAs) are non-coding RNAs measuring 20-22 nucleotides in length and are highly conserved among species. There are a number of miRNAs (miRNAs) in the human genome involved in various cellular processes including differentiation, proliferation, apoptosis, and tumorigenesis and progression (4). In previous years, the association between microRNA (miRNA) and lung cancer, in particular NSCLC, has become a focus of a number of studies: For example, miR-210 (5), miR-26a (6), and miR-212 (7) in lung cancer have been demonstrated to serve as oncogenes. By contrast, miR-1 (8), miR-126 (9), and miR-149 (10) serve as tumor suppressors in lung cancer. miR-512-5p is the 5 'terminal of miR-512 precursor. It was demonstrated that miR-512-5p level was increased in several tumor types $(11,12)$. A previous study revealed that miR-512-5p may induce apoptosis and inhibit glycolysis by targeting cyclin-dependent kinase inhibitor 1 (p21) in NSCLC cells (13). However, its roles in NSCLC have not yet been fully understood.

E26 transformation specific-1 (ETS1) is a type of proto-oncogene that is highly expressed in a variety of 
malignancies (14). ETS1 participates in tumor invasion, metastasis, angiogenesis, proliferation, differentiation and anti-apoptosis activities by regulating the expression of multiple genes (15-17). Dysregulation of ETS1 is frequent in NSCLC, but its regulation mechanism in NSCLC tumorigenesis remains unknown.

In the present study, the role of miR-512-5p in the development of NSCLC was examined; the results revealed that miR-512-5p was overexpressed in tumor cells and tissues, that it suppressed cell proliferation and invasion, induced apoptosis, and decreased ETS1 expression. Furthermore, it was confirmed that the miR-152-5p may inhibit ETS1 expression via targeting its 3 '-UTR, and then induce the apoptosis pathway and activate the intrinsic invasion pathway.

\section{Materials and methods}

Human tissue samples. The study was known and approved by the Ethics Committee of the Nanjing Gulou Hospital (Nanjing, China), Jiangsu Provincial Hospital of Traditional Chinese Medicine (Nanjing, China) and Affiliated Hospital of Xuzhou Medical College (Xuzhou, China). Clinical samples were collected from 181 patients with NSCLC between June 2014 and October 2017, and informed consent was granted. All patient diagnoses of NSCLC had been finally confirmed, and none of them patients had received any treatment.

Cell culture and transfection. Human NSCLC A549 and H1299 cell lines and human normal lung 16HBE cell lines were obtained from the Chinese Academy of Science Cell Bank (Shanghai, China), which were cultured in RPMI-1640 medium (Hyclone; GE Healthcare Life Sciences, Logan, UT, USA) supplemented with $10 \%$ fetal bovine serum (Biowest; VWR International Eurolab S.L., Barcelona, Spain) and 1\% penicillin/streptomycin (Gibco; Thermo Fisher Scientific, Inc., Waltham, MA, USA) at $37^{\circ} \mathrm{C}$ in $5 \% \mathrm{CO}_{2}$. miR-512-5p mimics, miR-512-5p inhibitor, negative control (NC) miRNA mimic (AM17110), and NC miRNA inhibitor (AM17010) were purchased from Ambion; Thermo Fisher Scientific, Inc. Small interfering (si)RNA against human ETS1 mRNA and the control siRNA were synthesized by Guangzhou RiboBio Co., Ltd. (Guangzhou, China). Transfection was performed with Lipofectamine ${ }^{\circledR} 2000$ reagent (Invitrogen; Thermo Fisher Scientific, Inc.), according to the manufacturer's protocol. After $12-48 \mathrm{~h}$, the subsequent experiments were performed. Briefly, $3 \times 10^{5}$ cells were cultured in 6 well plates. Subsequent to reaching 60-68\% confluence, cells were transfected with miRNA $(100 \mathrm{nM})$ or siRNA $(50 \mathrm{nM})$.

Reverse transcription quantitative polymerase chain reaction (RT-qPCR) analysis. In tissue and cell, total RNA was extracted with TRIzol ${ }^{\circledR}$ (Thermo Fisher Scientific, Inc.), and miRNA was extracted with miRcute miRNA Isolation kit (Tiangen Biotech, Co., Ltd., Beijing, China). Expression of miR-512-5p was analyzed by RT-qPCR using the TaqMan miR kit (Applied Biosystems; Thermo Fisher Scientific, Inc.), and expression of ETS1 mRNA was detected using PrimeScript ${ }^{\mathrm{TM}}$ reagent kit (TAKARA, Japan). U6 and GAPDH was used as the control for miRNA and mRNA, respectively. Data were acquired using a HT-7900 TaqMan instrument (Applied Biosystems;
Thermo Fisher Scientific, Inc.). The reaction consisted of a hot start $\left(10 \mathrm{~min}\right.$ at $\left.95^{\circ} \mathrm{C}\right)$, followed with 40 cycles of $15 \mathrm{sec}$ at $95^{\circ} \mathrm{C}$ and $60 \mathrm{sec}$ at $60^{\circ} \mathrm{C}$; the $2^{-\Delta \Delta \mathrm{Cq}}$ method was used (18). Each sample was detected in triplicate. The PCR primers for miR-512-5p were forward, 5'-CGoGCGGCACTCAGCCTTG AGGG-3' and reverse, 5'-GTGCAGGGTCCGAGGT-3'. The PCR primers for ETS1 were forward, 5'-AGCCGACTCTCA CCATCATC-3' and reverse, 5'-CAAGGCTTGGGACATCAT TT-3'. The PCR primers for U6 were forward, 5'-CTCGCT TCGGCAGCACA-3' and reverse, 5'-AACGCTTCACGA ATTTGCGT-3'. The PCR primers for GAPDH were forward, 5'-CTTAGATTTGGTCGTATTGG-3' and reverse, 5'-GAA GATGGTGATGGGATT-3'.

Cell proliferation assay. Cell proliferation was detected using a Cell Counting Kit (CCK)-8 (Dojindo Molecular Technologies, Inc., Kumamoto, Japan), and the assay was performed according to the protocol of the manufacturer. Briefly, cells were cultured in 96-well plates at 5,000 cells/well, and they were incubated at $37^{\circ} \mathrm{C}$ for $48 \mathrm{~h}$ following transfection. A total of $10 \mu \mathrm{lCCK}-8$ solution per well was added for $2 \mathrm{~h}$, and then examined. Viable cell numbers were detected at $450 \mathrm{~nm}$ with a Microplate Reader ELx808 (Bio-Tek Instruments, Inc., Winooski, VT, USA). Each experiment was performed in sextuplicate.

To confirm the CCK-8 assay results, a 5-ethynyl-2'-deoxyuridine (EdU) assay was also performed to measure cell proliferation. A total of 1,000 cells/well in a 96-well plate were serum-starved for $24 \mathrm{~h}$ following transfection, and the cells cultured for a further $24 \mathrm{~h}$. At $2 \mathrm{~h}$ prior to cell collection, EdU was labeled with EdU-labeling reagent (Invitrogen; Thermo Fisher Scientific, Inc.), which was then detected at a wavelength of $555 \mathrm{~nm}$ with a Click-iT assay kit (C10638; Thermo Fisher Scientific, Inc.) and images of $\geq 4$ fields per treatment condition captured (Leica Microsystems GmbH, Wetzlar, Germany). The percentage of cells in $\mathrm{S}$ phase was determined using ImageJ software version 1.45 (National Institutes of Health, Bethesda, MD, USA). Each data point represents the average percentage of labeled cells among the 4 images.

Cell apoptosis assay. Cell apoptosis was detected by the fluorescein isothiocyanate (FITC)-Annexin V/propidium iodide (PI) Apoptosis Detection kit (BD Pharmingen; BD Biosciences, San Jose, CA, USA) according to the manufacturer's protocol. All cells were collected for apoptosis analysis at $48 \mathrm{~h}$ post-transfection. Then, cells were stained for $5 \mathrm{~min}$ at room temperature with Annexin V-FITC (5 ml) and PI $(5 \mathrm{ml})$. Cell apoptosis was analyzed by a flow cytometer (Beckman Coulter, Inc., Brea, CA, USA). FlowJo version 7.6 (FlowJo LLC, Ashland, OR, USA) was used to calculate the apoptosis rate. All analyses were performed in triplicate.

Wound healing assay. The cells were seeded with $5 \times 10^{5}$ into 6 -well plates, and the cells were lightly scratched using a $10 \mu 1$ sterile pipette tip in the central axis of the plate when the density reached $\sim 70 \%$ following transfection. Following culture for $48 \mathrm{~h}$, cells were imaged with a Nikon Ts 2 inverted microscope, at $\times 200$ magnification. The extent of cell migration was quantified using ImageJ version 1.46 (National Institutes of Health). The percentage of wound closure was calculated as 
follows: [(wound area at $0 \mathrm{~h}$-wound area at $24 \mathrm{~h}$ )/wound area at $0 \mathrm{~h}$ ] $\times 100 \%$. A total of 3 replicates were performed.

Transwell assay. The cells were transfected for $12 \mathrm{~h}$, then placed in the upper Transwell chamber (Corning Incorporated, Corning, NY, USA) with an insert pre-coated with Matrigel (BD Biosciences) and incubated for $12 \mathrm{~h}$ at $37^{\circ} \mathrm{C}$. The chambers were cultured in 24-well plates, and RPMI-1640 containing $20 \%$ FBS was added to lower chamber. Following incubation for $24 \mathrm{~h}$ at $37^{\circ} \mathrm{C}$, the cells that had penetrated across the membranes were fixed with $90 \%$ methanol for $10 \mathrm{~min}$ at room temperature, stained with $0.1 \%$ crystal violet for $20 \mathrm{~min}$ and counted under an inverted light microscope at x200 magnification. A total of 3 replicates were obtained.

Luciferase assay. The A549 and H1299 cells were seeded onto 24-well plates and co-transfected with either $25 \mathrm{nM}$ miR-512-5p mimics or miR-NC and $200 \mathrm{ng}$ pGL3-ETS1-3'UTR or pGL3-ETS1-mut-3'UTR using Lipofectamine ${ }^{\circledR} 2000$ reagent (Thermo Fisher Scientific, Inc.), and the reporter plasmids were obtained from Promega Corporation (Madison, WI, USA). After $36 \mathrm{~h}$, luciferase activity was measured using the dual luciferase assay system (Promega Corporation). Renilla luciferase was used to normalize luciferase activity. All analyses were performed in triplicate.

Target prediction. For bioinformatics analysis, PicTar (http://pictar.mdc-berlin.de/), miRanda (http://www.microrna. org) and TargetScan (http://www.targetscan.org/) were used.

Western blot analysis. Following transfection, cells of $80 \%$ density were lysed using radioimmunoprecipitation assay buffer (Beyotime Institute of Biotechnology, Haimen, China) containing a Protease Inhibitor Cocktail (Promega Corporation) for $30 \mathrm{~min}$ The protein was collected, and the concentrations were measured using a BCA assay kit (Beyotime Institute of Biotechnology). Proteins $(40 \mu \mathrm{g})$ were then separated with $10 \%$ SDS-PAGE, and then transferred onto a polyvinylidene fluoride membrane. Membranes were blocked at room temperature in 5\% non-fat milk for $1 \mathrm{~h}$, and immunoblotted with anti-caspase-3 (sc-271759), anti-caspase-7 (sc-365034), anti-B-cell lymphoma-2 (Bcl-2; sc-130307), anti-Bcl-2-associated X protein (Bax; sc-23959), anti-matrix metalloproteinase (MMP)-2 (sc-53630), anti-MMP-9 (sc-12759), anti-phosphorylated (p)-p38 mitogen-activated protein kinase (p-p38 MAPK; sc-7973), anti-p38 MAPK (sc-81621), anti-p-c-Jun N-terminal kinases (p-JNK; (sc-293138), anti-JNK (sc-137020), anti-p-extracellular signal-regulated kinase (p-ERK; sc-81492), anti-ERK (sc-135900), anti-ETS1 (sc-55581) and GAPDH (sc-47724; all Santa Cruz Biotechnology, Inc., Dallas, TX, USA) antibodies at $4^{\circ} \mathrm{C}$ overnight; all antibodies were used at a dilution of 1:1,000. The secondary antibodies against rabbit or mouse IgG (Beyotime Institute of Biotechnology) were incubated for $2 \mathrm{~h}$ at RT. Following washing of the membranes three times, signals were visualized with enhanced chemiluminescence (ECL Wuhan Boster Biological Technology, Ltd., Wuhan, China) and analyzed using ImageJ version 1.45 (National Institutes of Health).

Statistical analysis. Statistical analysis was performed using GraphPad software 5.0 (GraphPad Software, Inc., La Jolla,
CA, USA) and the results are presented as the mean \pm standard deviation. Differences between two groups were determined by Student's t-test. Comparisons between multiple group were performed using one-way analysis of variance with a Scheffe post-hoc test for subsequent individual group comparisons. $\mathrm{P}<0.01$ was considered to indicate a statistically significant difference.

\section{Results}

Downregulation of miR-512-5p in NSCLC tissues and cell lines. To assess the expression levels of miR-512-5p in NSCLC, the expression level of miR-512-5p was detected in tumor tissues and adjacent normal tissues from patients with NSCLC by RT-qPCR. The expression levels of miR-512-5p were decreased in tumor tissues compared with those in adjacent normal tissues (Fig. 1A). NSCLC A549 and H1299 cell lines exhibited decreased miR-512-5p expression compared with the normal lung $16 \mathrm{HBE}$ cell line (Fig. 1B). To additionally determine the effect of miR-512-5p on NSCLC cell lines, miR-512-5p and NC mimics were transfected into the cells. As indicated in Fig. 1C and D, the expression levels of miR-512-5p were increased following transfection with $\mathrm{miR}-512-5 \mathrm{p}$ mimics in A549 and H1299 cells.

miR-512-5p suppresses NSCLC cell proliferation and induces apoptosis in vitro. In the present study, the cell proliferation was assessed by CCK-8 and EdU assays in A549 and H1299 cells. Compared with the NC mimics, miR-512-5p mimics exhibited a significant inhibition of cell proliferation in A549 and H1299 cells (Fig. 2A and B), and the results of EdU assay were coincident with CCK-8 (Fig. 2C and D). In addition, d total apoptosis was measured, and it was identified that the apoptosis rate was increased in miR-512-5p mimic-treated cells (Fig. 3A and B). Furthermore, proapoptotic proteins (Bcl-2, Bax, caspase-3 and caspase-7) were detected by western blot analysis. The results indicated that the expression levels of Bax, caspase-3 and caspase-7 were significantly increased, and the expression levels of Bcl-2 were decreased (Fig. 3C and D). Taken together, these data revealed that the overexpression of miR-512-5p may markedly suppress cell proliferation and induced apoptosis in NSCLC cells.

miR-512-5p inhibits the cell migratory and invasive capacities in A549 and H1299 cells. The effect of miR-512-5p on cell migration and invasion in A549 and H1299 cells was detected by scratch and Transwell assays. miR-512-5p mimic-treated cells exhibited a significant decrease in their wound-closing capacities in the scratch assay (Fig. 4A and B), and significantly decreased numbers of invading cells in the Transwell assay (Fig. 4C and D) compared with NC mimic-treated cells in A549 and H1299 cells. The results of the western blot analysis demonstrated that the expression levels of MMP-2 and MMP-9 were significantly inhibited in A549 and H1299 cells (Fig. 4E and F).

ETS1 is a target of miR-512-5p. ETS1 is important in regulating cell invasion, metastasis, proliferation and apoptosis, and the present study identified that ETS1 mRNA and protein levels were decreased following transfection with miR-512-5p 
A

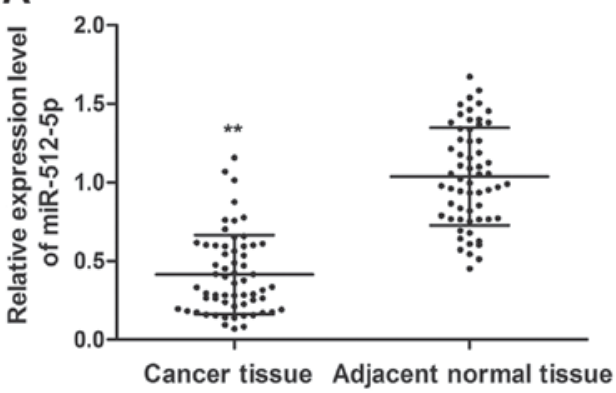

C

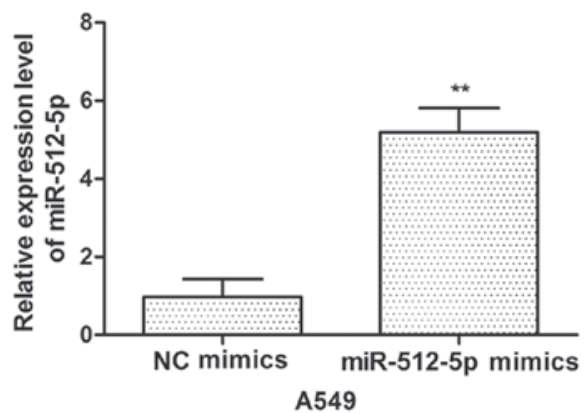

B

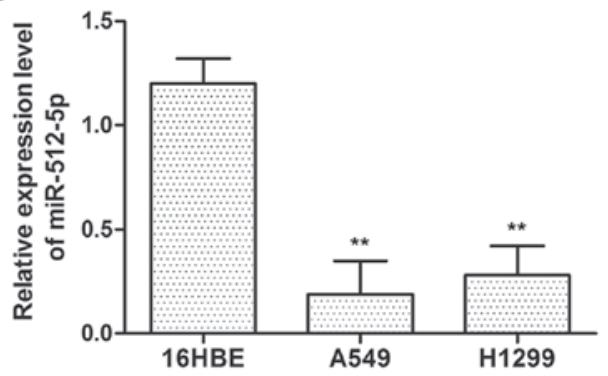

D

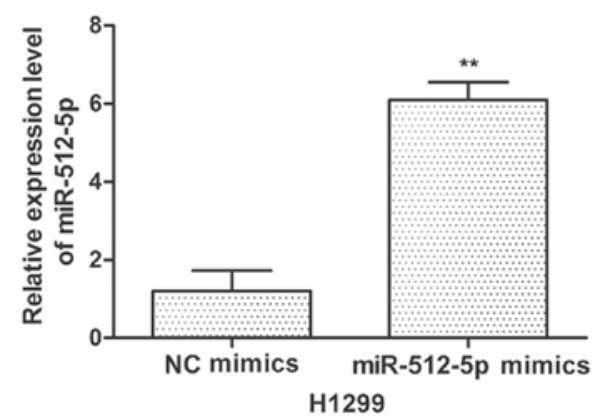

Figure 1. The result of expression of miR-512-5p in non-small cell lung cancer cell. miR-512-5p was detected in (A) non-small cell lung cancer tissues and (B) cell lines by RT-qPCR. RT-qPCR analysis was performed to detect miR-512-5p expression following transfection with NC mimics and miR-512-5p mimics in (C) A549 and (D) H1299 cells. Data are presented as mean \pm standard deviation. ${ }^{* *} \mathrm{P}<0.01$ vs. NC/normal cell lines and tissues. miR, microRNA; RT-qPCR, reverse transcription quantitative polymerase chain reaction; NC, negative control.

A

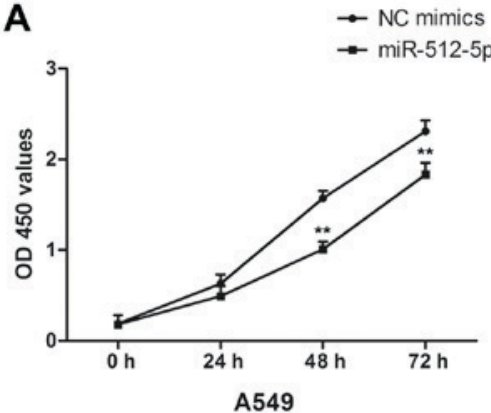

C

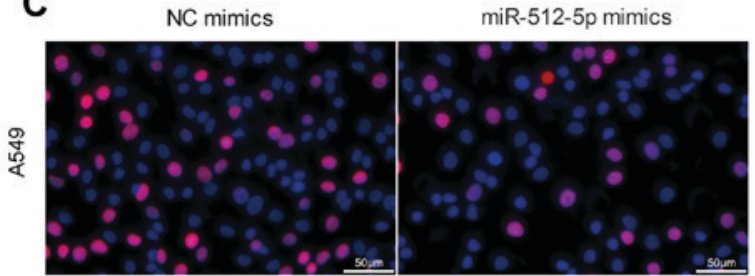

D

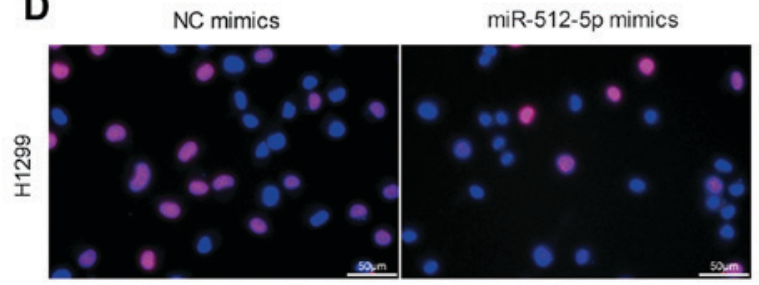

B
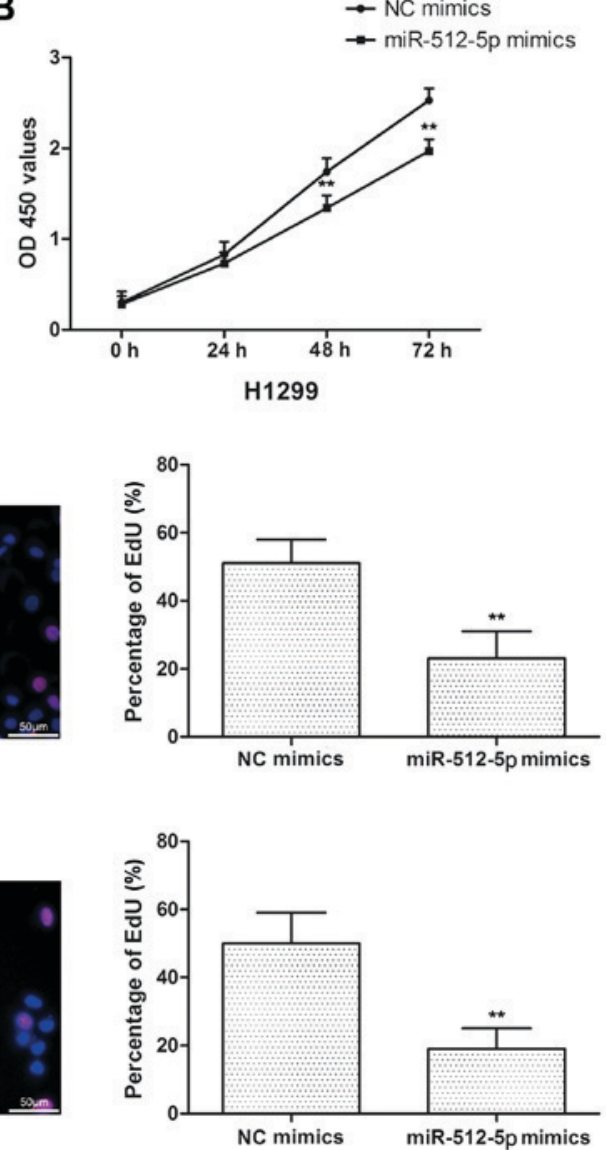

Figure 2. The effect of miR-512-5p on cell proliferation in A549 and H1299 cells. CCK-8 assay was performed to detected proliferation after transfection with miR-512-5p mimics at the indicated time points in (A) A549 and (B) H1299 cells. An EdU assay also was used to detected proliferation following transfection with miR-512-5p mimics for $48 \mathrm{~h}$ in (C) A549 and (D) H1299 cells. Data are presented as mean \pm standard deviation. ${ }^{* *} \mathrm{P}<0.01 \mathrm{vs.} \mathrm{NC} \mathrm{mimics.} \mathrm{miR,} \mathrm{microRNA;}$ $\mathrm{NC}$, negative control; OD, optical density. 
A

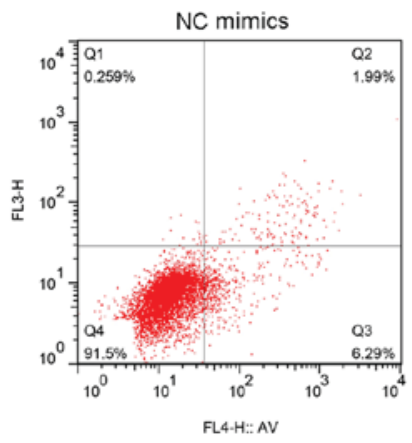

B

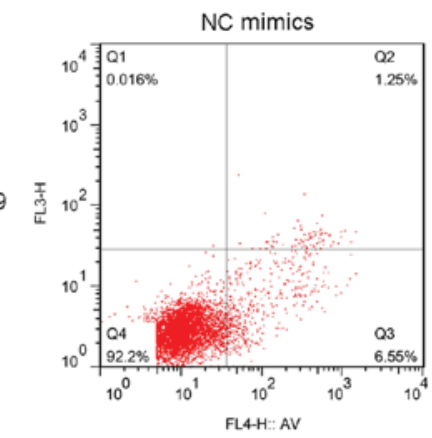

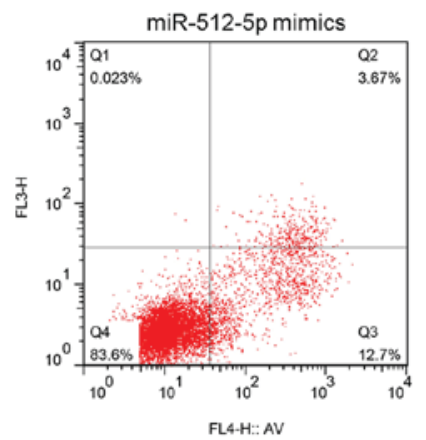

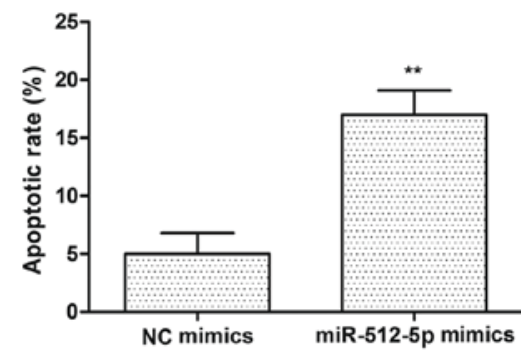

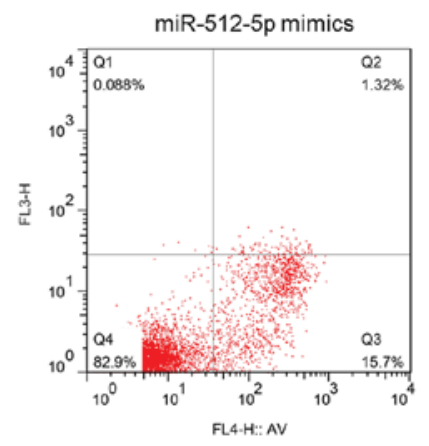

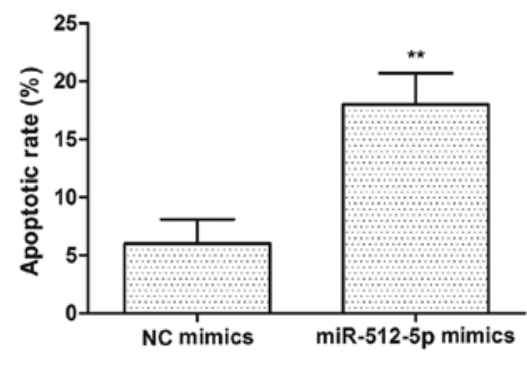

C
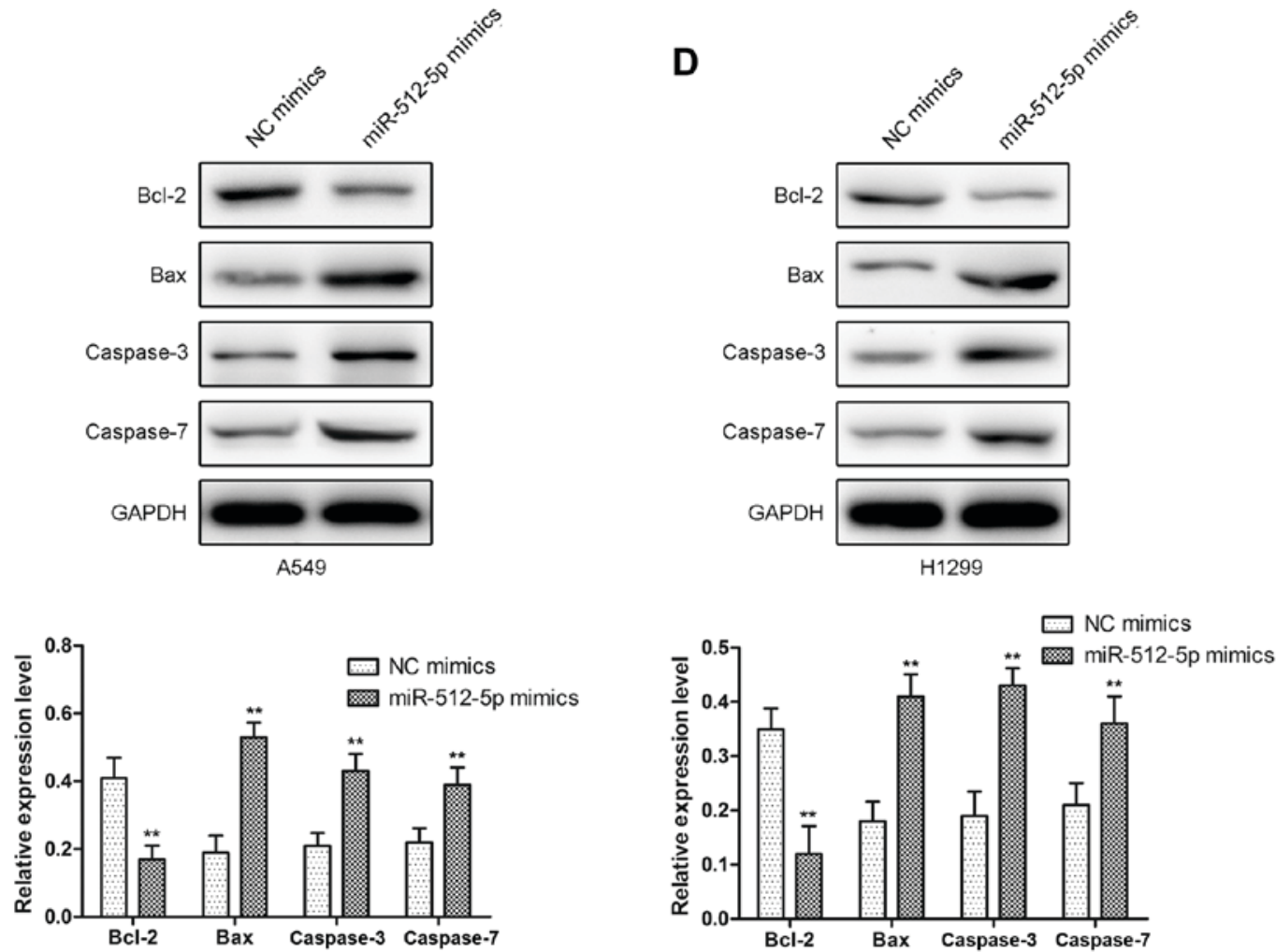

Figure 3. The effect of miR-512-5p on cell apoptosis in A549 and H1299 cells Apoptosis assays were performed following transfection with miR-512-5p mimics for $48 \mathrm{~h}$ in (A) A549 and (B) H1299 cells. Apoptosis proteins (Bcl-2, Bax, caspase-3 and caspase-7) were detected by western blot analysis following transfection with miR-512-5p mimics in (C) A549 and (D) H1299 cells. Data are presented as mean \pm standard deviation. ${ }^{* *} \mathrm{P}<0.01$ vs. NC mimics. miR, microRNA; NC, negative control; Bcl-2, B-cell lymphoma-2; Bax, Bcl-2-associated X protein.

mimics in A549 and H1299 cells (Fig. 5A and B). We hypothesized that ETS1 was regulated by miR-512-5p in A549 and H1299 cells, and the ETS1 gene was predicted to have at least one potential binding site at its 3'-UTR for miR-512-5p. To validate the interaction between ETS1 and miR-512-5p, luciferase reporter assays were performed using the miR-512-5p target sequences of wild-type ETS1 and mutated ETS1 in A549 and H1299 cells. The results indicated that overexpression of miR-512-5p significantly decreased luciferase expression in wild-type ETS1-3'-UTR transfected cells compared with control in A549 and H1299 cells, and there was no change in mutated ETS1-3'-UTR-transfected cells (Fig. 5C and D). These data revealed that miR-512-5p may regulate ETS1 by directly binding to the 3'-UTR in A549 and H1299 
A

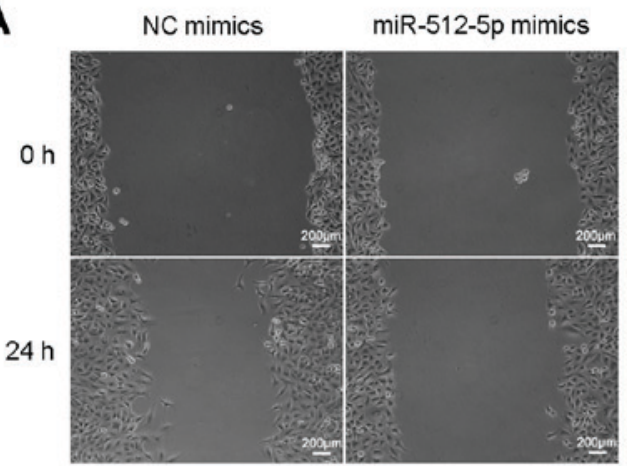

A549

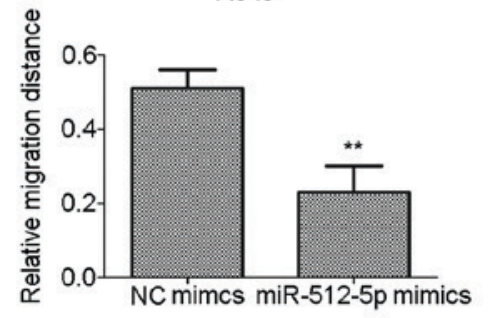

C
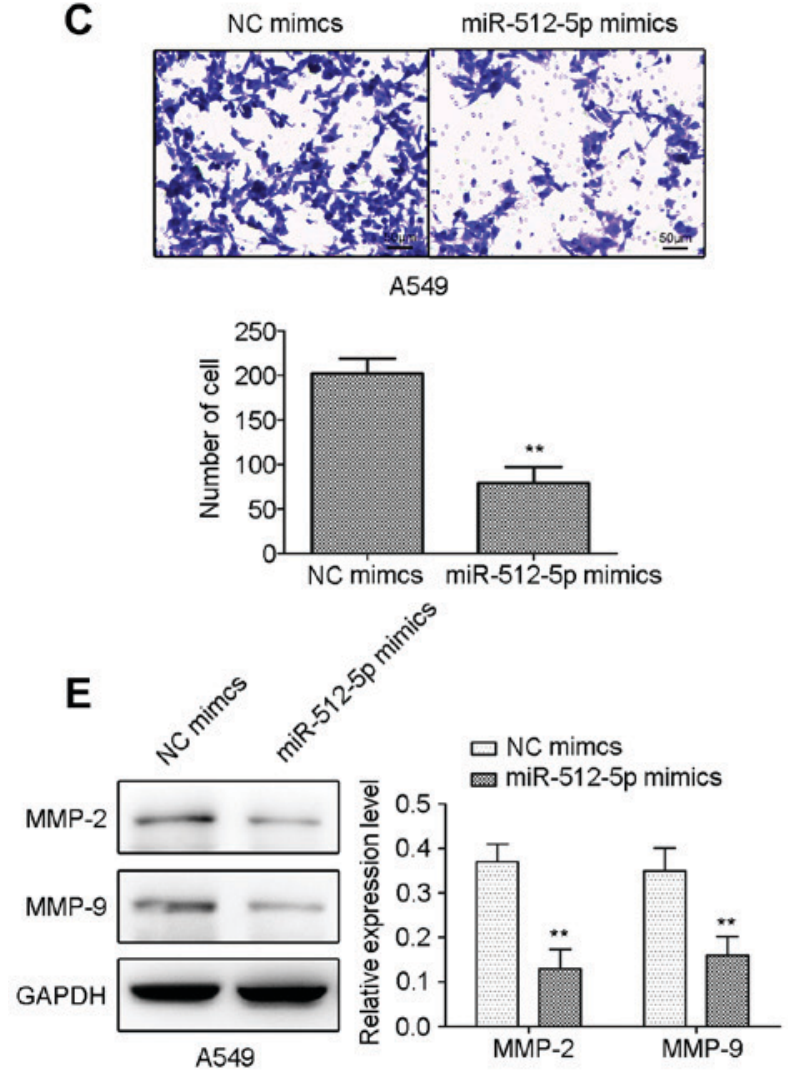

C mimcs miR-512-5p mimics

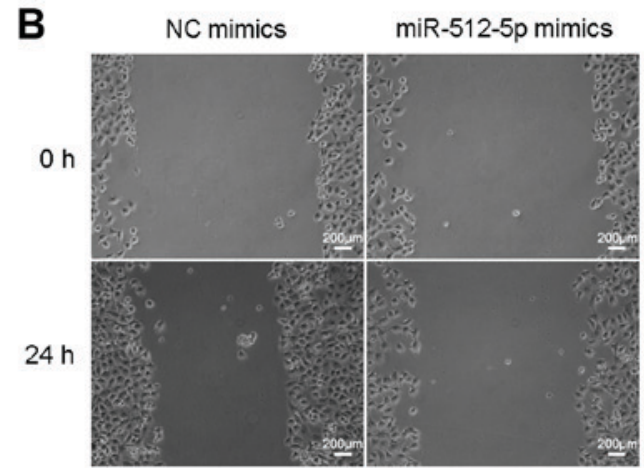

H1299

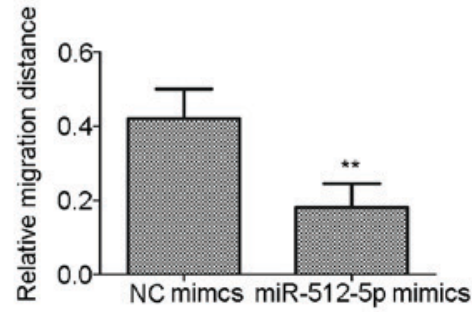

D
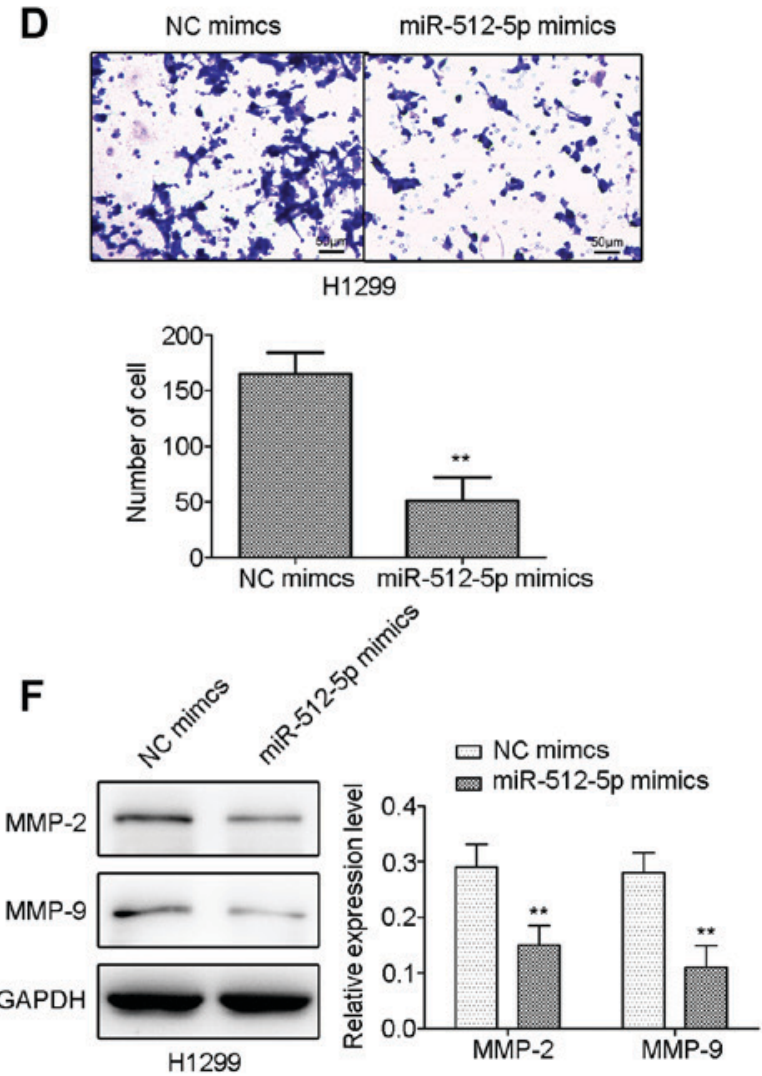

Figure 4. The effect of miR-512-5p on cell migration and invasion in A549 and H1299 cells. Cell migration was detected by wound healing assay following transfection with miR-512-5p mimics in (A) A549 and (B) H1299 cells. Cell invasion was detected by Transwell assay following transfection with miR-512-5p mimics in (C) A549 and (D) H1299 cells. MMP-2 and MMP-9 were detected by western blot analysis following transfection with miR-512-5p mimics in (E) A549 and (F) H1299 cells. Data are presented as mean \pm standard deviation. ${ }^{* *} \mathrm{P}<0.01 \mathrm{vs.} \mathrm{NC} \mathrm{mimics.} \mathrm{miR,} \mathrm{microRNA;} \mathrm{NC,} \mathrm{negative} \mathrm{control;}$ MMP, matrix metalloproteinase.

Downregulation of miR-512-5p attenuates the effect of si-ETS1 on proliferation, invasion, migration and apoptosis of NSCLC cells. To demonstrate that miR-512-5p affects NSCLC cells through ETS1, the effect of si-ETS1 and si-ETS1 in the presence of an miR-512-5p inhibitor in NSCLC cells was investigated. Following transfection of si-ETS1 into the cells, downregulation of ETS1 was confirmed by RT-qPCR and western blot analysis (Fig. 6A and B). Downregulation of ETS1 inhibited proliferation (Fig. 6C-F), induced apoptosis (Fig. 7) and migration (Fig. 8) in the A549 and H1299 cells, increased the expression of Bax, caspase- 3 and caspase-7, and decreased the expression of Bcl-2, MMP-2 and MMP-9. However, the presence of an miR-512-5p inhibitor reversed the effect of si-ETS1 on A549 and H1299 cells. These data demonstrated 
A

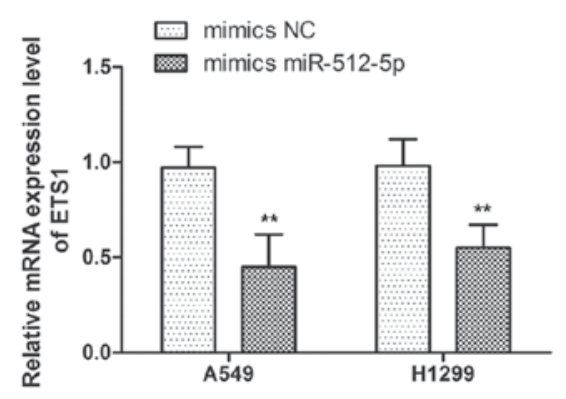

B

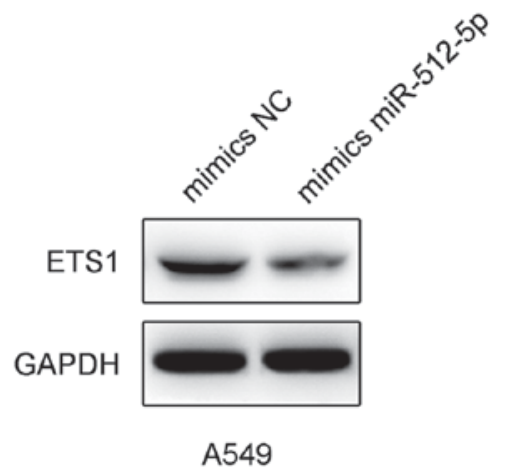

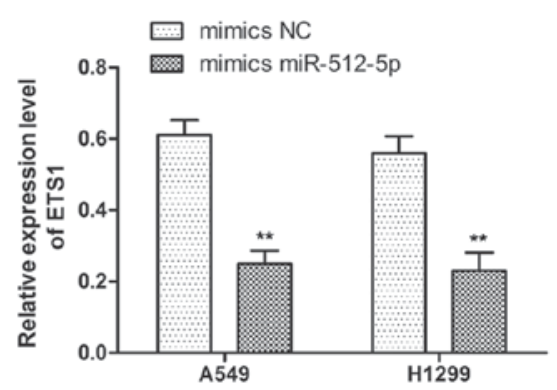

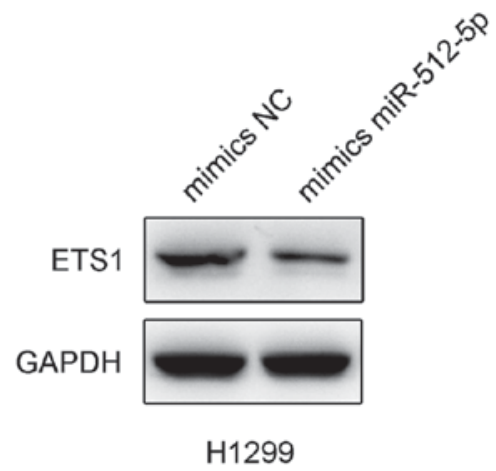

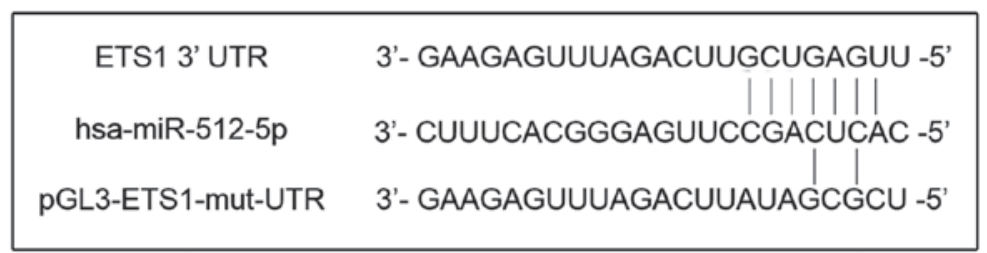

C

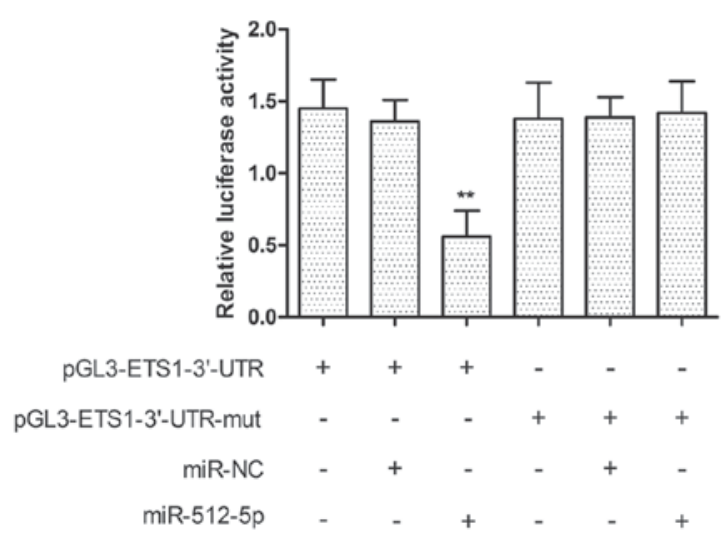

D

$\mathrm{H} 1299$

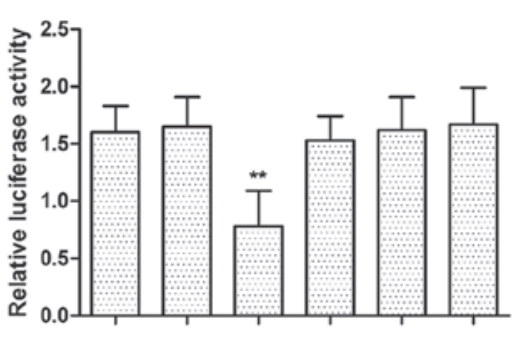

pGL3-ETS1-3'-UTR

PGL3-ETS1-3'-UTR-mut

miR-NC

miR-512-5p

Figure 5. miR-512-5p target to regulate the expression of ETS1. (A) Reverse transcription quantitative polymerase chain reaction and (B) western blot analysis were used to detect ETS1 following transfection with mimics miR-512-5p in A549 and H1299 cells. Luciferase activity was analyzed following co-transfection of (C) A549 and (D) H1299 cells with pGL3-ETS1-3'-UTR, pGL3-ETS1-3'-UTR-mut and miR-512-5p or NC mimics. Data are presented as mean \pm standard deviation. ${ }^{* *} \mathrm{P}<0.01$ vs. NC. ETS1, E26 transformation specific-1; miR, microRNA; NC, negative control; UTR, untranslated region; hsa, Homo sapiens; mut, mutant.

that the effects of miR-512-5p on proliferation, invasion, migration and apoptosis of NSCLC cells may be induced by regulating ETS1.

\section{Discussion}

Increasing evidence indicates that the abnormal expression of target genes mediated by miRNA is involved in a number of pathological processes (19). The miRNA coding region is often located in fragile genomic areas, where gene amplification or deletion easily occurs in tumors (20). Multiple studies have also confirmed that a large number of abnormally expressed miRNA exist in tumor cell lines and tumor tissues, and many target genes regulated by these miRNA are closely associated with the development of tumors (21).

miR-512-5p is located at chromosome 19q13.42, which is processed by miR-512-1 or miR-521-2 (12). From previous observations and studies, profiling of miRNA expression in 
A
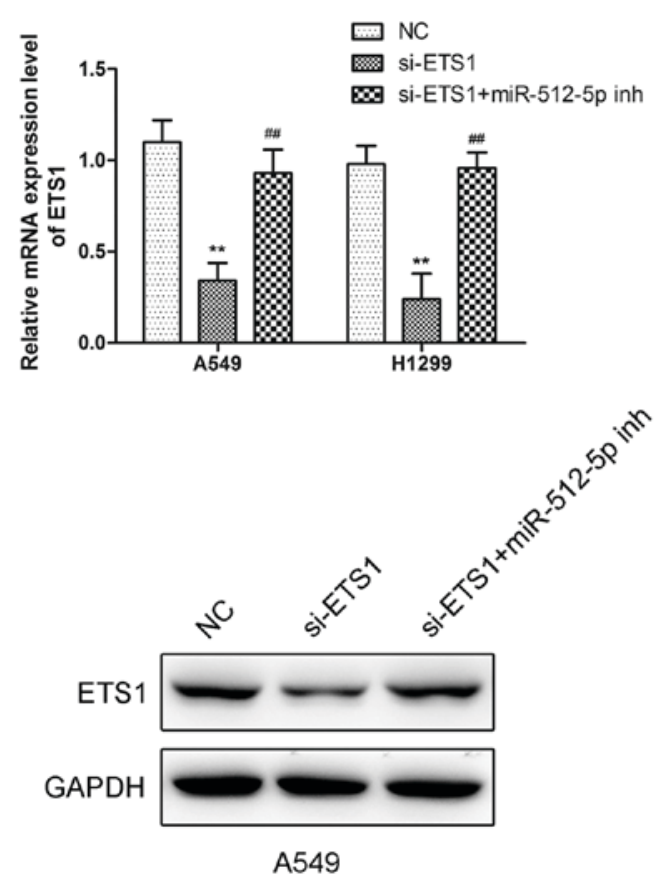

C

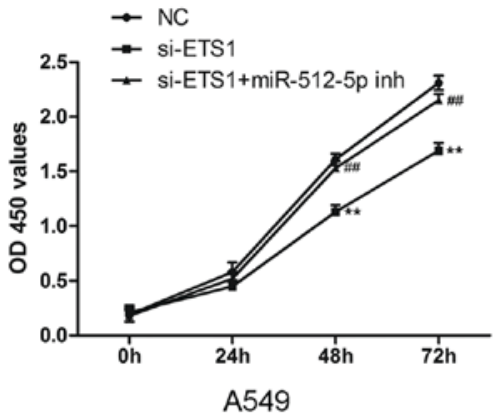

B

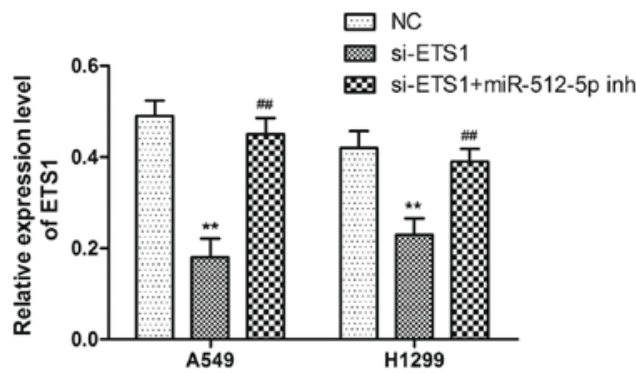

E

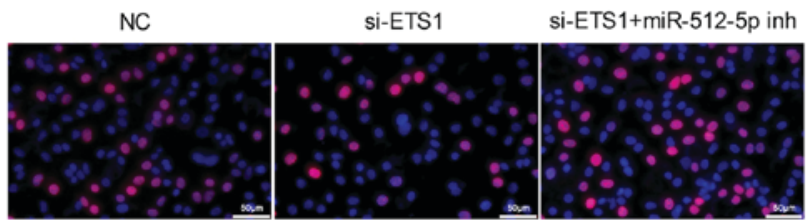

$\mathbf{F}$

NC

si-ETS1 si-ETS1+miR-512-5p inh

H1299
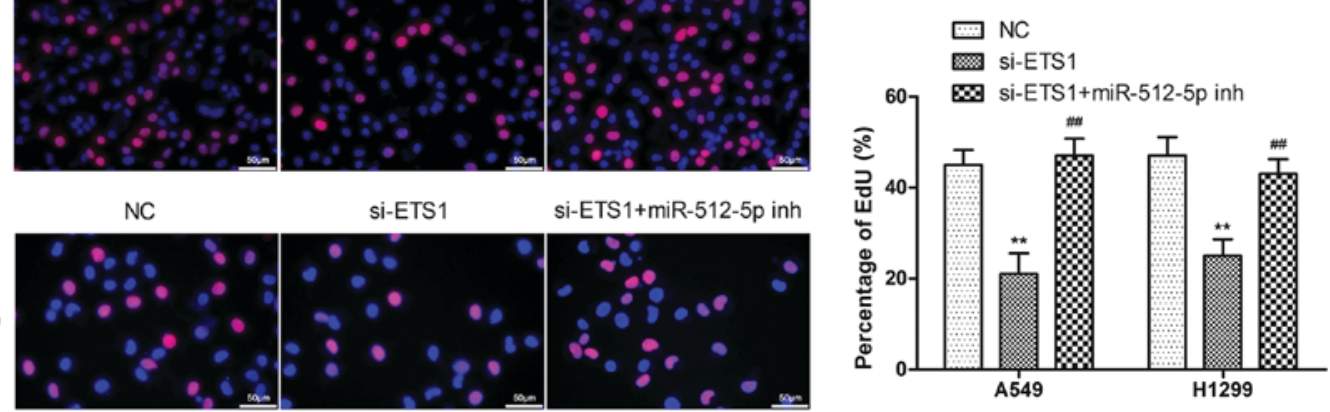

Figure 6. The effect of knockdown of ETS1 on cell proliferation in A549 and H1299 cells. (A) and (B) The expression of ETS1 was measured by RT-PCR and western blot analysis following transfection with si-ETS1 or an miR-512-5p inhibitor in the presence of si-ETS1 in A549 and H1299 cells. CCK-8 assays were performed to detect cell proliferation following transfection with si-ETS1 or an miR-512-5p inhibitor in the presence of si-ETS1 in (C) A549 and (D) H1299 cells. EdU assays were performed to detect cell proliferation following transfection with si-ETS1 or an miR-512-5p inhibitor in the presence of si-ETS1 in (E) A549 and (F) H1299 cells. Data are presented as mean \pm standard deviation. ${ }^{* *} \mathrm{P}<0.01$ vs. NC; ${ }^{\# \# /} \mathrm{P}<0.01$ vs. si-ETS1. ETS1, E26 transformation specific-1; miR, microRNA; NC, negative control; si, small interfering; inh, inhibitor.

357 patients with stage I NSCLC identified miR-512 as an indicator of good prognosis (12). miR-152-5p induced apoptosis and inhibited glycolysis in NSCLC by targeting p21 (13). Overexpression of miR-512-5p suppressed tumor growth by regulating telomerase reverse transcriptase in head and neck squamous cell carcinoma in vitro and in vivo (22).

In the present study, the results indicated that miR-512-5p was downregulated in NSCLC tissues and cells compared with normal controls. Furthermore, the effects of miR-512-5p on NSCLC cell proliferation, apoptosis, migratory and invasive capabilities was assessed in vitro, and it was identified that miR-512-5p overexpression decreased the proliferative, migratory and invasive abilities, and induced apoptosis. Chu et al (13) demonstrated that miR-512-5p induced apoptosis in NSCLC cells, similar to the data from the present study. The present study identified that miR-512-5p may inhibit cell migratory and invasive abilities in NSCLC cells, but Chu et al (13) did not investigate these factors. They 
A

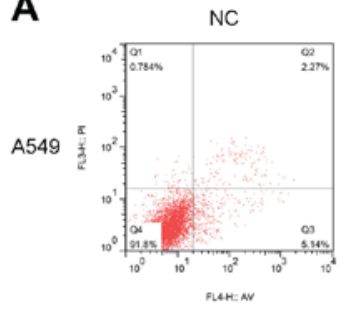

B
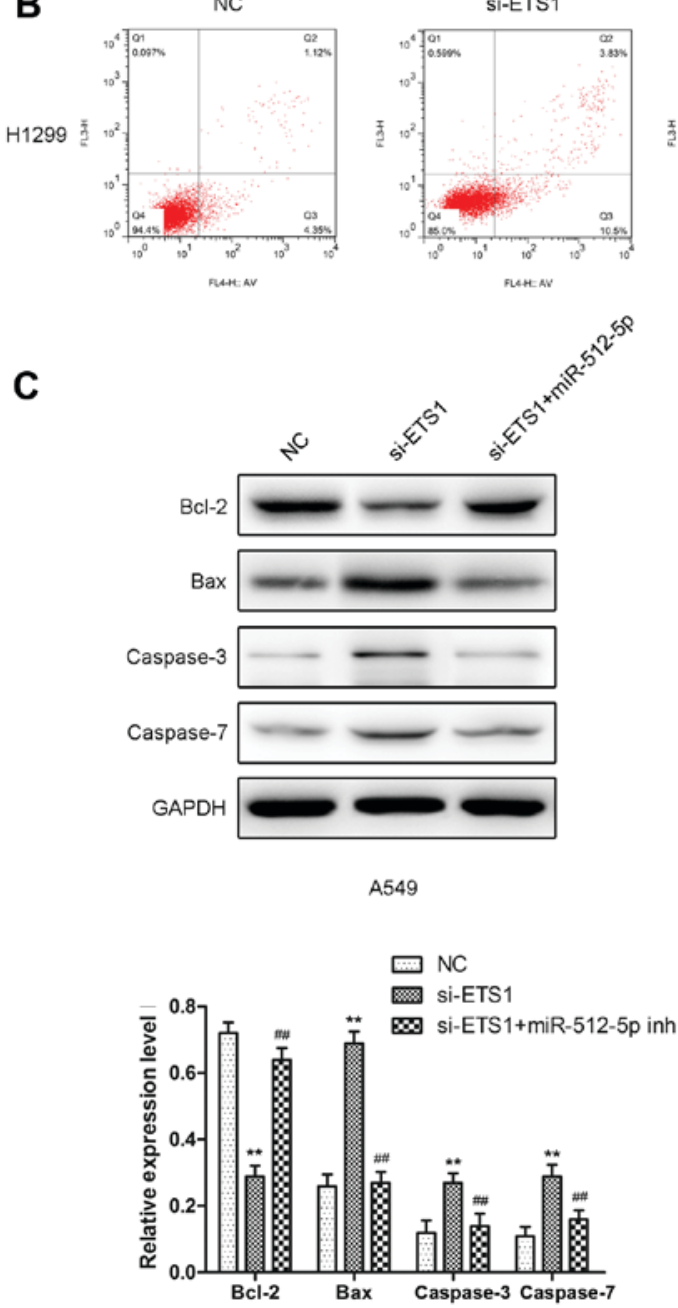

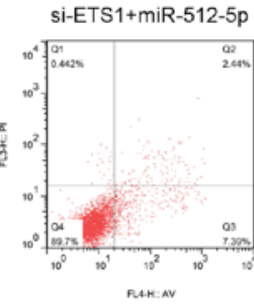

si-ETS1+miR-512-5p
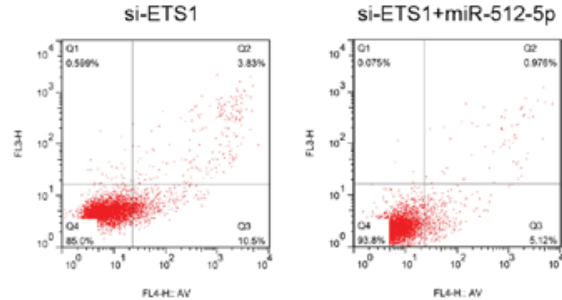

(n)
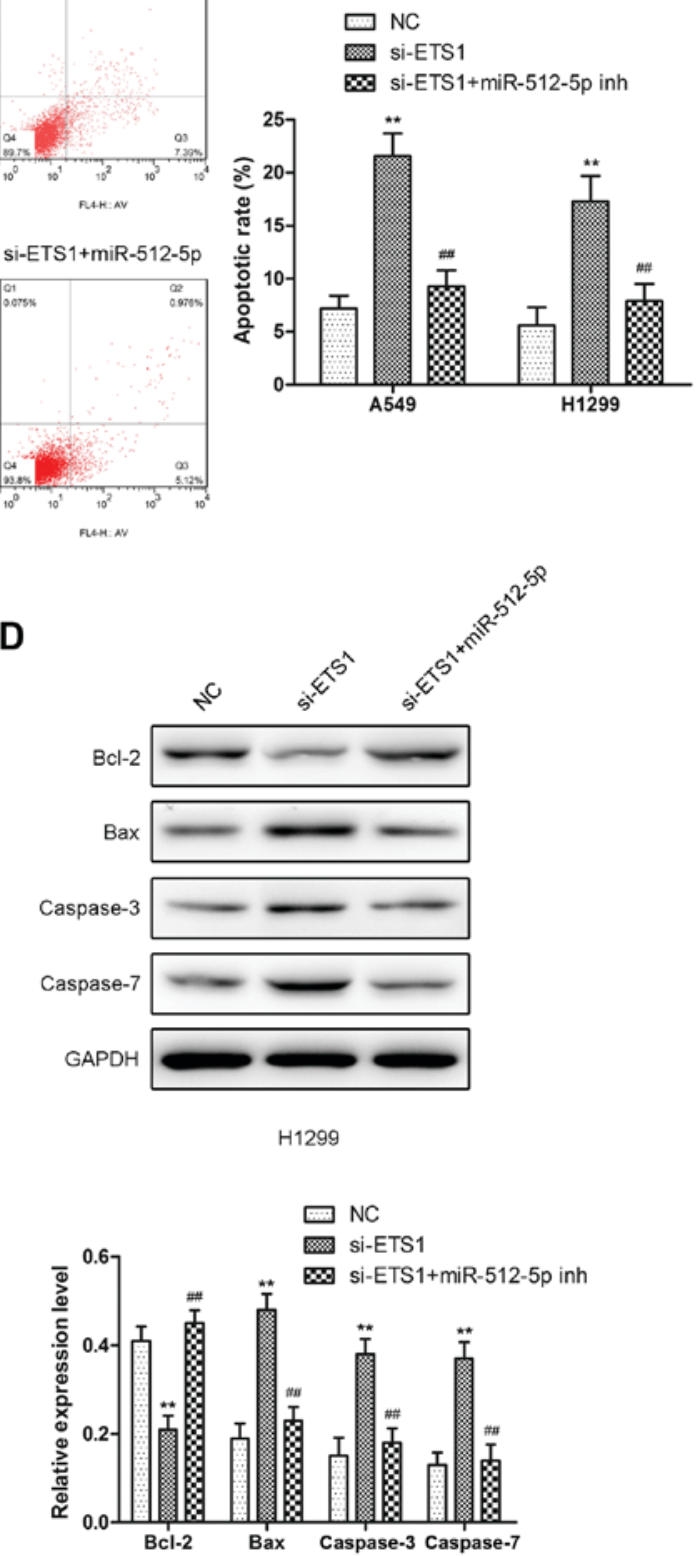

Figure 7. The effect of knockdown of ETS1 on cell apoptosis in A549 and H1299 cells. Apoptosis assays were performed following transfection with si-ETS1 or an miR-512-5p inhibitor in the presence of si-ETS1 for $48 \mathrm{~h}$ in (A) A549 and (B) H1299 cells. Relative apoptosis proteins (Bcl-2, Bax, caspase-3, and caspase-7) were detected by western blot analysis following transfection with si-ETS1 or an miR-512-5p inhibitor in the presence of si-ETS1 in (C) A549 and (D) H1299 cells. Data are presented as mean \pm standard deviation. ${ }^{* *} \mathrm{P}<0.01$ vs. NC; ${ }^{\# \#} \mathrm{P}<0.01$ vs. si-ETS1. ETS1, E26 transformation specific-1; si, small interfering; miR, microRNA; NC, negative control; Bcl-2, B-cell lymphoma-2; Bax, Bcl-2-associated X protein; inh, inhibitor.

demonstrated that miR-512-5p overexpression had no effect on cell proliferation by CCK-8 assay, conflicting with the data from the present study. However, the results from the present study suggested that miR-512-5p overexpression decreased proliferation, using an EdU assay. The differences between the data from the present study and those from Chu et al (13) may be due to factors including detection methods and errors. The expression and regulation of the Bcl-2 and caspase families are key factors affecting cell apoptosis $(23,24)$. MMPs promote the invasion of cancer cells to surrounding tissues by degradation of the extracellular matrix (25). The results from the present study indicated that miR-512-5p overexpression significantly increased expression of Bax, caspase-3 and caspase-9, and decreased expression of Bcl-2, MMP-2 and MMP-9 in NSCLC cells. The data from Chu et al (13) indicated that miR-512-5p overexpression induced NSCLC cells apoptosis by regulating p21. Those results and the results from the present study indicated that multiple signaling pathways participate in NSCLC cell apoptosis of miR-512-5p-regulation. Chu et al (13) also revealed that miR-512-5p inhibited glycolysis in A549 and H1299 cell lines; this was not investigated in the present study. The data from the present study revealed miR-512-5p serves as a tumor suppressor.

ETS1 is highly expressed in a variety of malignant tumors. It participates in cell invasion, metastasis, proliferation and apoptosis by regulating the expression of a variety of genes, 
A

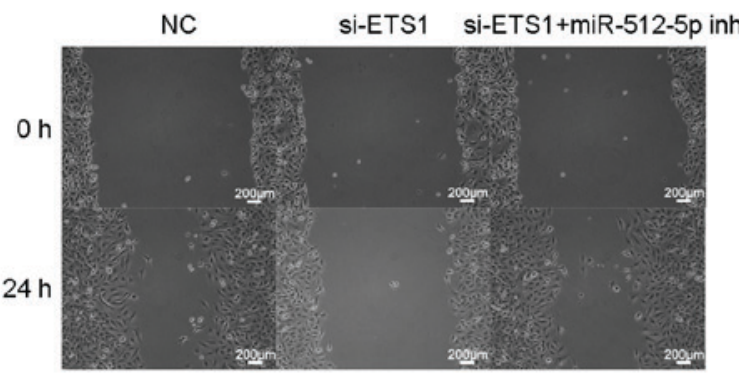

B

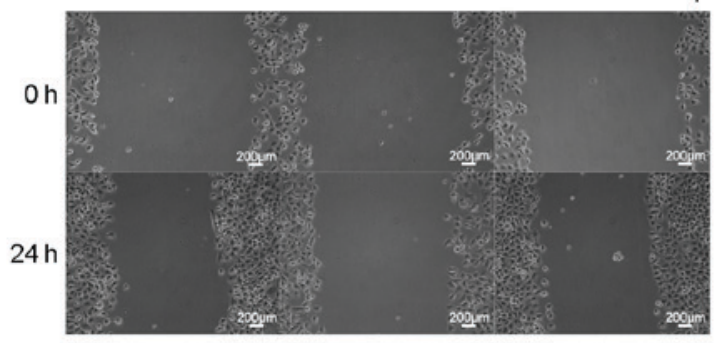

A549

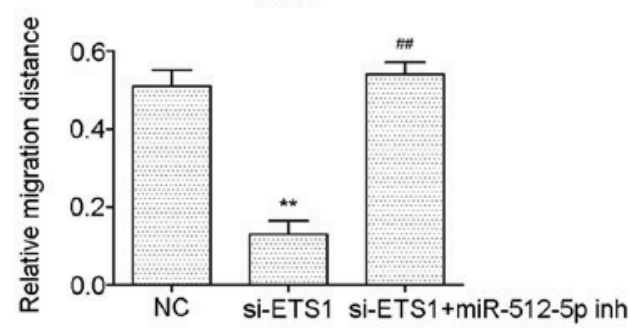

H1299

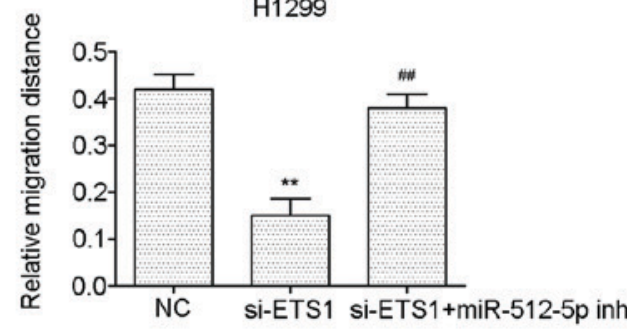

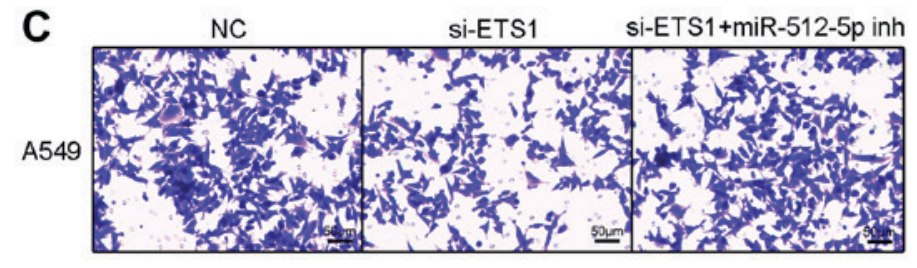

D
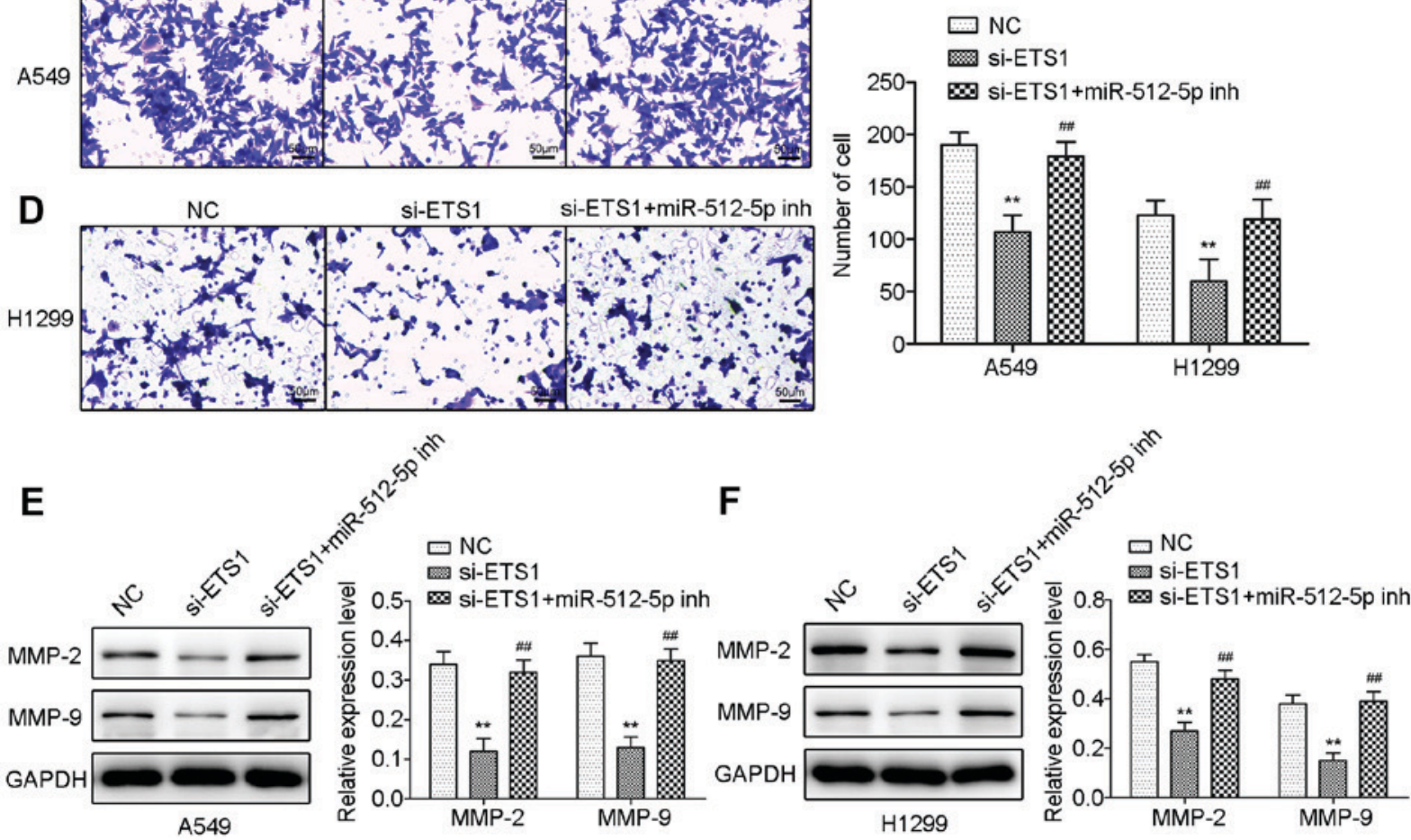

Figure 8. The effect of knockdown of ETS1 on cell migration and invasion in A549 and H1299 cells. Cell migration was detected by wound healing assay following transfection with si-ETS1 or an miR-512-5p inhibitor in the presence of si-ETS1 in (A) A549 and (B) H1299 cells. Cell invasion was detected by Transwell assay following transfection with si-ETS1 or an miR-512-5p inhibitor in the presence of si-ETS1 in (C) A549 and (D) H1299 cells. MMP-2 and MMP-9 were detected by western blot analysis following transfection with si-ETS1 or an miR-512-5p inhibitor in the presence of si-ETS1 in (E) A549 and (F) H1299 cells. Data are presented as mean \pm standard deviation. ${ }^{* *} \mathrm{P}<0.01$ vs. NC; ${ }^{\# \#} \mathrm{P}<0.01$ vs. si-ETS1. ETS1, E26 transformation specific-1; si, small interfering; miR, microRNA; NC, negative control; MMP, matrix metalloproteinase; inh, inhibitor.

including MMPs, Bcl-2 and Bax (26-28). The results of the RT-qPCR and western blot analysis suggested that ETS1 was overexpressed in NSCLC cells, and miR-512-5p may decrease the expression of ETS1. Target prediction analysis additionally indicated that miR-512-5p may target ETS1. The prediction was confirmed by luciferase assays, and the results indicated that miR-512-5p directly targeted ETS1 mRNA and inhibited its translation. Following transfection of the cells with si-ETS1, it was identified that the results were concomitant with the miR-512-5p overexpression data, and in the presence of si-ETS1, an miR-512-5p inhibitor rescued the effect of si-ETS1 in NSCLC cells.

Taken together, the present study demonstrated that miR-512-5p is significantly downregulated in NSCLC tissues and cells, and may regulate ETS1 expression to affect NSCLC cell proliferation, migration, invasion and apoptosis. These data suggest that miR-512-5p may become a potential prognostic marker and/or therapeutic target in NSCLC. 


\section{Acknowledgements}

Not applicable

\section{Funding}

No funding was received.

\section{Availability of data and materials}

The datasets used and/or analyzed during the current study are available from the corresponding author on reasonable request.

\section{Authors' contributions}

PS conceived and designed the study. BC and ST performed the experiments. HT and YC conducted the analysis of data. PS wrote the manuscript. All authors read and approved the manuscript.

\section{Ethics approval and consent to participate}

The study was approved by the Ethics Committee of the Nanjing Gulou Hospital (Nanjing, China), Jiangsu Provincial Hospital of Traditional Chinese Medicine (Nanjing, China) and Affiliated Hospital of Xuzhou Medical College (Xuzhou, China).

\section{Patient consent for publication}

Informed consent was provided.

\section{Competing interests}

The authors declare that they have no competing interests.

\section{References}

1. Yoshimi I and Sobue T: International comparison in cancer statistics: Eastern Asia (2). Jpn J Clin Oncol 34: 759-763, 2004.

2. Zhang L: SC17.02 Lung Cancer in China: Challenges and Perspectives. J Thor Oncol 12: S113-S114, 2017.

3. Higgins KA, O'Connell K, Liu Y, Gillespie TW, McDonald MW, Pillai RN, Patel KR, Patel PR, Robinson CG, Simone CB II, et al: National cancer database analysis of proton versus photon radiotherapy in non-small cell lung cancer (NSCLC). Int J Radiat Oncol Biol Phys 97: 128-137, 2017.

4. Ludwig N, Leidinger P, Becker K, Backes C, Fehlmann T, Pallasch C, Rheinheimer S, Meder B, Stähler C, Meese E and Keller A: Distribution of miRNA expression across human tissues. Nucleic Acids Res 44: 3865-3877, 2016.

5. Puisségur MP, Mazure NM, Bertero T, Pradelli L, Grosso S, Robbe-Sermesant K, Maurin T, Lebrigand K, Cardinaud B, Hofman V, et al: miR-210 is overexpressed in late stages of lung cancer and mediates mitochondrial alterations associated with modulation of HIF-1 activity. Cell Death Differ 18: 465-478, 2011.

6. Liu B, Wu X, Liu B, Wang C, Liu Y, Zhou Q and Xu K: MiR-26a enhances metastasis potential of lung cancer cells via AKT pathway by targeting PTEN. Biochim Biophys Acta 1822: 1692-1704, 2012.

7. Li Y, Zhang D, Chen C, Zhenchao R, Li Y and Huang Y: MicroRNA-212 displays tumor-promoting properties in non-small cell lung cancer cells and targets the hedgehog pathway receptorPTCH1. Mol Biol Cell 23: 1423, 2012.
8. Nasser MW, Datta J, Nuovo G, Kutay H, Motiwala T, Majumder S, Wang B, Suster S, Jacob ST and Ghoshal K: Down-regulation of Micro-RNA-1 (miR-1) in lung cancer. Suppression of tumorigenic property of lung cancer cells and their sensitization to doxorubicin-induced apoptosis by miR-1. J Biol Chem 283: 33394-33405, 2008.

9. Sun Y, Bai Y, Zhang F, Wang Y, Guo Y and Guo L: miR-126 inhibits non-small cell lung cancer cells proliferation by targeting EGFL7. Biochem Biophys Res Commun 391: 1483-1489, 2010.

10. Ke Y, Zhao W, Xiong J and Cao R: miR-149 Inhibits Non-Small-Cell Lung Cancer Cells EMT by Targeting FOXM1. Biochem Res Int 2013: 506731, 2013.

11. Cheung TH, Man KN, Yu MY, Yim SF, Siu NS, Lo KW, Doran G, Wong RR, Wang VW, Smith DI, et al: . Cell Cycle 11: 2876-2884, 2012 .

12. Adi Harel S, Bossel Ben-Moshe N, Aylon Y, Bublik DR, Moskovits N, Toperoff G, Azaiza D, Biagoni F, Fuchs G, Wilder S, et al: Reactivation of epigenetically silenced miR-512 and miR-373 sensitizes lung cancer cells to cisplatin and restricts tumor growth. Cell Death Differ 22: 1328-1340, 2015.

13. Chu K, Gao G, Yang X, Ren S, Li Y, Wu H, Huang Y and Zhou C: miR-512-5p induces apoptosis and inhibits glycolysis by targeting p21 in non-small cell lung cancer cells. Int J Oncol 48: 577-586, 2016.

14. Dittmer J: The biology of the Ets1 proto-oncogene. Mol Cancer 2: 29, 2003.

15. Zhang Y, Yan LX, Wu QN, Du ZM, Chen J, Liao DZ, Huang MY, Hou JH, Wu QL, Zeng MS, et al: miR-125b is methylated and functions as a tumor suppressor by regulating the ETS1 proto-oncogene in human invasive breast cancer. Cancer Res 71: 3552-3562, 2011

16. Zheng L, Qi T, Yang D, Qi M, Li D, Xiang X, Huang K and Tong Q: microRNA-9 suppresses the proliferation, invasion and metastasis of gastric cancer cells through targeting cyclin D1 and Ets1. PLoS One 8: e55719, 2013.

17. Pei H, Li C, Adereth Y, Hsu T, Watson DK and Li R: Caspase-1 is a direct target gene of ETS1 and plays a role in ETS1-induced apoptosis. Cancer Res 65: 7205-7213, 2005.

18. Livak KJ and Schmittgen TD: Analysis of relative gene expression data using real-time quantitative PCR and the 2(-Delta Delta C(T)) method. Methods 25: 402-408, 2001.

19. Hsu SD, Tseng YT, Shrestha S, Lin YL, Khaleel A, Chou CH, Chu CF, Huang HY, Lin CM, Ho SY, et al: miRTarBase update 2014: An information resource for experimentally validated miRNA-target interactions. Nucleic Acids Res 42: D78-D85, 2014.

20. Eulalio A, Huntzinger E and Izaurralde E: Getting to the root of miRNA-mediated gene silencing. Cell 132: 9-14, 2008.

21. Carissimi C, Fulci V and Macino G: MicroRNAs: Novel regulators of immunity. Autoimmun Rev 8: 520-524, 2009.

22. Li J, Lei H, Xu Y and Tao Z: miR-512-5p suppresses tumor growth by targeting hTERT in telomerase positive head and neck squamous cell carcinoma in vitro and in vivo. PLoS One 10: e0135265, 2015.

23. Cory S, Huang DC and Adams JM: The Bcl-2 family: Roles in cell survival and oncogenesis. Oncogene 22: 8590-8607, 2003.

24. Ola MS, Nawaz M and Ahsan $\mathrm{H}$ : Role of Bcl-2 family proteins and caspases in the regulation of apoptosis. Mol Cell Biochem 351: 41-58, 2011.

25. Nabeshima K, Inoue T, Shimao Y and Sameshima T: Matrix metalloproteinases in tumor invasion: Role for cell migration. Pathol Int 52: 255-264, 2002.

26. Puzovic V, Brcic I, Ranogajec I and Jakicrazumovic J: Prognostic values of ETS-1, MMP-2 and MMP-9 expression and co-expression in breast cancer patients. Neoplasma 61: 439-446, 2014.

27. Yu Z and Shah DM: Curcumin down-regulates Ets-1 and Bcl-2 expression in human endometrial carcinoma HEC-1-A cells. Gynecol Oncol 106: 541-548, 2007.

28. Nakazawa Y, Suzuki M, Manabe N, Yamada T, Kihara-Negishi F, Sakurai T, Tenen DG, Iwama A, Mochizuki M and Oikawa T: Cooperative interaction between ETS1 and GFI1 transcription factors in the repression of Bax gene expression. Oncogene 26: 3541-3550, 2007.

This work is licensed under a Creative Commons Attribution-NonCommercial-NoDerivatives 4.0 International (CC BY-NC-ND 4.0) License. 